\title{
AMÉRICA LATINA Y EL CARIBE HACIA 1898 SEGÚN LA DIPLOMACIA VATICANA
}

\author{
POR
}

ANTÓN M. PAZOS

Universidad de Navarra

\section{Resumen}

La Santa Sede comenzó a interesarse por América Latina a finales de siglo con la finalidad de articular una Iglesia continental. El artículo analiza la correspondencia de la Santa Sede con países y obispados de América.

\section{ABSTRACT}

Latin America and Caribe according to the Vatican diplomacy

The Holy See begun to take interest in Latin America at the end of the last century. The aim was to articulate a continental Church. This article analyse the correspondence between the Holy See and Bishop from America.

\section{AMÉRICA LATINA EN EL PONTIFICADO DE LEÓN XIII}

El estudio de la situación religiosa de América Latina en 1898 nos lleva necesariamente a insertarlo en las grandes líneas del pontificado de León XIII, que dedicó no poca atención al nuevo continente. Se podría decir sin temor a exagerar que la construcción de la América Latina católica, tal como la entendemos hoy -es decir, con un episcopado latinoamericano unitario-, es obra de León XIII. Ciertamente la actuación leoniana en América Latina hay que conectarla a su vez con las líneas dominantes de su pontificado, aunque estuvieran ya algo desvaídas en tomo a 1898 , en los años finales del reinado. 


\subsection{Interés por América Latina durante el pontificado de León XIII}

Sin ser -ni de lejos - un objetivo primordial, la Santa Sede empezó a interesarse por los asuntos americanos a fines de siglo y estableció las bases para la articulación de una Iglesia continental. Voy ahora a limitarme a los años que coinciden con el nombramiento de Rampolla como Secretario de Estado', en 1887. En ese año el Papa escribió al nuevo Secretario una carta programática en la que le planteaba los objetivos de la diplomacia pontificia para cada una de las naciones con las que existían relaciones. Ciertamente el tenor era claramente europocéntrico, pero mencionaba ya a América Latina como un territorio al que había que dedicar especiales cuidados ${ }^{2}$. Algunas encíclicas de años posteriores nos dan pistas sobre cuáles eran esos "especiales cuidados".

En 1888 escribió a los obispos americanos sobre los emigrantes italianos ${ }^{3}$; en 1892 a toda América con motivo del IV centenario'; en 1894 a los obispos peruanos indicándoles qué temas le parecían mas oportunos para el concilio de Lima5; en 1897 resumió en la Carta Apostólica Trans oceanum los privilegios concedidos a lo largo de los siglos a los territorios americanos, especialmente en relación con los indios y negros ${ }^{6}$, y en 1898 dirigió a todos los obispos la carta Cum Diuturnum ${ }^{7}$ con motivo del inminente Concilio Plenario de América Latina de 1899, Concilio que resumirá el trabajo de la diplomacia vaticana en Latinoamérica durante la última década del siglo.

1 Rampolla es Secretario de Estado desde el 1 de junio de 1887 al 20 de julio de 1903, en que muere León XIII (DE MARCHI, GIUSEPPE, Le Nunziafure Apostoliche dal 1800 al 1956, Edizioni di Storia e Letteratura, Roma 1957, p. 13).

2 «Le strette attinenze di origine, di lingua e di religione, come ancora la fermezza medesima nell'avita fede, che unioniscono alla Spagnuola le popolazioni dell'America di mezzodi, $\mathrm{Ci}$ invitano a non disgiungerle nelle speciali cure che saremo per rivolgere del pari a comune loro vantaggio» (Lettera di Sua Santita Papa Leone XIII al Cardinale Mariano Rampolla suo Segretario di Stato, en Acta Sanctae Sedis, XX (1887) 8).

3 Epistola Quam Aerumnosa ad Archiepiscopos et Episcopos Americae: quibus commendat cives italos inopia illuc migrantes, en Acta Sanctae Sedis, XXI (1888) 258-260 (se dirige a los obispos de Estados Unidos, animándoles a enviar alumnos al recién abierto Colegio Piacentino para promover vocaciones que misionen con los emigrantes italianos en América, pero como veremos, el problema era el mismo en América Latina).

4 Epistola Quarto abeunte saeculo ad Archiepiscopos et Episcopos ex Hispania, Italia et utraque America. De Christophoro Colombo, en Acta Sanctae Sedis, XXV (1892) 3-7.

5 Litterae Sanctissimi D. N. Leonis Papae XIII ad Antistites Peruviae, con motivo del conciljo celebrado en Lima, en Acta Sanctae Sedis, XXVI (1894) 648-652. La primera recomendación que les hace es que se ocupen de la formación de los candidatos al sacerdocio.

6 Litterae apostolicae Trans Oceanum in forma Brevis Sanctissimi D. N. Leonis PP. XIII de privilegiis America Latinae, en Acta Sanctae Sedis, XXIX (1897) 659-663.

7 Litterae Cum diuturnum ad Ordinarios America Latinae qui Romam deligunt pro consiliis inter eodem habendis, en Acta Sanctae Sedis, XXXI (1898) 321-322.

La América y la Espața Contemporánea

Hispania Sacra 49 (1997) 


\subsection{Cuestiones de interés en el ámbito latinoamericano en relación con} las líneas maestras del pontificado de Leín XIII

No se trata ahora de intentar resumir las líneas generales de un pontificado tan variado y discutido como largo, sino de entresacar las más características del período para ver si se reflejan - y cómo- en América Latina.

Puntos pacíficamente aceptados que muestran la orientación de la Iglesia en tiempos de León XIII son ${ }^{8}$ :

a) El esfuerzo por recuperar el poder civil, que se enmarca en una nueva política de cristiandad en la que la Santa Sede - tras perder los Estados pontificios- busca actuar como potencia intemacional y que se manifestó en una acción diplomática de gran alcance. Casi todos los autores destacan el interés de León XIII en establecer nuevos vínculos con los gobiemos superando fricciones. La experiencia diplomática que Joaquino Pecci tuvo antes de ser Papa se manifiesta casi siempre en reconocer que son mejores las relaciones difíciles que las inexistentes. Se traducirá en un esfuerzo por ampliar la red diplomática en América y por evitar rupturas. El interés por América probablemente quedó reforzado por la experiencia de Rampolla como nuncio en España ${ }^{9}$ - donde contactaría con representantes latinoamericanos-y también por incluir la nunciatura española a Cuba y Puerto Rico.

b) El esfuerzo para ampliar los límites de la cristiandad por medio de las misiones, como nuevas zonas de influencia de la Iglesia. Para América Latina se hizo hincapié sobre todo en las misiones indias, que volvieron a desarrollarse a fines de siglo después de los abandonos posteriores a la Emancipación.

c) El interés por los inmigrantes, tanto por su atención espiritual - muy descuidada hasta entonces-, como por la influencia que podía suponer

8 Remito como sintesis mínjma pero reciente y precisa a LEVILLAIN, PHILIPPE, Leon XII, en LeVIllain, PHILIPPE (dir.), Dictionnaire historique de la papauté, Fayard, Paris 1994, pp. 1035-8. Con más desarrollo, vid. el trabajo tambiên sintêtico de AUBERT, ROGER, Leone XIII: Tradizione e progreso, en METZLER, JOSEF (dir.), Storia della Chiesa, XXII/1, La Chiesa e la società industriale (1878-1922), Edizioni Paoline, Cinisello Balsamo [1990], pp. 61-106. Una de las pocas sintesis en historias de la Iglesia recientes sobre América Latina es HENKEL, WILLI, La Chiesa in America Latina, en METZLER, JOSEF (dir.) Storia della Chiesa, XXIV, Dalle missioni alle chiese locali (18461965). Edizione Paoline, Cinisello Balsamo 1990, pp. 477-644. Interesa también, porque ofrece visiones del pontificado globales, y no sólo italianas, el estudio de TrinCHESE, STEFANO, Sviluppi missionari e orientamenti sociali. Chiesa e stato nel magistero di Leone XII, en DE ROSA, GABRIELE (dir.) Storia dellitalia religiosa, t. III, L'etá contemporanea, Editori Laterza, Roma-Bari 1995, pp. 61-86.

9 Entre 1882 y 1887. 
para la Iglesia la llegada de numerosos fieles católicos en países de minorias. Para fines de siglo en América Latina, suponía la posibilidad de inyectar católicos practicantes --blancos - en una sociedad criolla descristianizada o librepensadora. Y el inconveniente de que engrosarian el número de los no practicantes si no se conseguía ayuda espiritual para ellos, sobre todo párrocos de las naciones de origen.

d) La utilización de los laicos como elemento de presencia de la Iglesia aunque dependiendo del clero desde el punto de vista organizativo. Se reflejó en la insistencia para mejorar la actuación de periodistas y escritores católicos que opusiesen sus escritos y periódicos a los liberales. La subordinación de las organizaciones laicas a la jerarquía llevó también a intentar controlar las tradicionales cofradías, consideradas muchas veces como excesivamente independientes. Brasil fue el ejemplo extremo, en donde llegó a plantearse la eliminación —o el abandono- de las cofradías tradicionales sutituyéndolas por otras con laicos de confianza.

e) Reacción contra el racionalismo y el laicismo, en continuidad con la línea de Pío IX. Está presente por doquier en América, que se veía como un continente ganado por el liberalismo. Puede afirmarse que las preocupaciones eclesiásticas latinoamericanas son algo más rancias que las europeas, y en el terreno ideológico da la impresión de estar más en la época de Pío IX que en la de León XIII. Quizá por esto mismo un aspecto característico del Papa de la Rerum novarum -la preocupación obrera y sindical- apenas se refleja en Latinoamérica: aparecerá décadas más tarde, ya en el siglo XX. De algún modo, manifiesta la diferente evolución de la sociedad americana. También en esta línea estarían las frecuentes denuncias y condenas de la masonería, que aparece como omnipresente en América Latina.

f) Refuerzo de la centralización romana, en línea también con lo iniciado en tiempos de Pío IX. Podría concretarse en un mayor control de los asuntos americanos por las congregaciones romanas, especialmente la de Asuntos Eclesiásticos Extraordinarios. Sin embargo, no todo lo que se presenta como centralización —o síntoma de tal- lo es. Así, Aubert considera la celebración en Roma del Concilio Plenario Latino Americano como una muestra más del carácter absorbente de la curia, cuando la realidad es que se hizo en Roma porque los países americanos no lograron ponerse de acuerdo en una ciudad americana aceptada por todos ${ }^{10}$.

10 «En el 1900 la prima assemblea dell'episcopato dell'America del Sud si svolse in Vaticano sotto la presidenza del papa stesso» (AUBERT, ROGER, Leone XIII..., p. 79). En realidad fue en 1889, no en 1900. Las sesiones se realizaron en el colegio Pio Latino-Americano (no en el Vaticano, por tanto) y tuvieron lugar en Roma por los enfrentamientos entre las distintas naciones para decidir la sede. 
g) Utilización de los điplomáticos como elemento de información, control y estímulo religioso, además de instrumentos de diálogo con los gobiernos ante los que estaban acreditados. León XIII rechazó desde el principio la postura victimista de Pío IX como prisionero del Vaticano y elaboró un ambicioso plan de presencia internacional de la Santa Sede, el mayor concebido hasta entonces. Los instrumentos empleados fueron los nuncios y delegados apostólicos, concebidos ahora no sólo como representantes diplomáticos ante los gobiemos sino como verdaderos motores de transformación social y religiosa según las directrices romanas. No deja de tener interés mencionar que el documento que suele presentarse como síntesis de esta nueva diplomacia sea la carta del Secretario de Estado Jacobini a Rampolla criticando la opinión expresada en «El siglo futuro» que reducía el papel de los nuncios al de meros diplomáticos ${ }^{11}$. En esa carta se precisaba que los nuncios representaban ampliamente al Papa en sus demarcaciones, y que los obispos y los fieles debían plegarse a sus indicaciones, pues eran quienes conocían las directrices papales para la Iglesia en esa nación. En efecto, durante todo el pontificado, los diplomáticos jugaron un papel clave en la visión centralizadora de la Iglesia y en la remodelación cristiana del mundo ${ }^{12}$. Lo hi-

Tampoco el concilio fue presidido por el papa, sino por todos los arzobispos presentes, en turnos de tres días con carácter temporal de delegados pontificios, segun acuerdo de una primera reunión «de los once Arzobispos [presentes] después de palpar las muchas susceptibilidades y dificultades» (Carta de Eulogio Gillow, Arzobispo de Oaxaca a Nicolas Averardi, Visitador apostólico en México, Roma, 3-VI-1899, en Archivo Segreto Vaticano (en adelante ASV), Visita Apostolica Messico, Busta XIII, fol. 445v. Sobre el concilio plenario el trabajo más reciente y completo es el de PICCARDO, DLEGo R., Historia del Concilio Plenario Latinoamericano (Roma 1899). Tesis Doctoral, Universidad de Navaпта, 1991, pro manuscripto. La cita de Gillow en p. 232.

11 Epistola Emmi D. Card. Iacobini exteris Pontificiae Ditionis negotiis curandis praepositi ad Excellentissimum Nuntium Apostolicum Matriti commorantem, quoad nonnulla principia perniciosa $a b$ ephemeride «siglo futuro" publicata, en Acta Sanctae Sedis, 17 (1884-85) 561-569. Es la respuesta a un artículo de Francisco María de las Rivas planteando que en cuestiones religiosas y de conciencia los obispos son independientes de los nuncios, a los que calificaba de meros representantes «diplomáticos», cargando el término de sentido peyorativo. Sobre la repercusión del conflicto en España, y la actitud de Cándido Nocedal y los integristas, vid. ANDRÉs-GALLEGO, JOSÉ, La politica religiosa en España, 1889-19J3, Editora Nacional, Madrid 1975, pp. 23-24.

12 Así se entiende mejor el planteamiento de acción social o de acción católica en sentido amplio, fomentado por Roma en las últimas décadas del siglo, en el que participaron las fuerzas católicas, pero dirigidas desde el centro por medio de los delegados pontificios: «... tutta la dottrina sociale de Leone XIII, insieme al suo vasto progetto diplomatico e alla politica concordataria dei cardinali segretari di Stato, da Franchi a Rampolla, componeva un piano di affermazione internazionale della Santa sede mai ricordato prima; [...] Funzionali a tale progetto universale di rimodellazione cristiana deli'orbe terrestre erano il ripensamento centralistico del ruolo dei nunzi e dei delegati apostolici, in una visione meglio controlata della rete diplomatica pontificia, e inoltre il paralelo ridimensionamento degli episcopati nazionali, condotto attraverso l'aumento del controllo per il tramite delle nunziature, 
cieron también en América, en donde podríamos decir que, paradójicamente, tuvieron más éxito en la actuación unificadora del episcopado y los fieles que en el propiamente diplomático.

\section{LA DIPLOMACIA VATICANA EN AMÉRICA LATINA}

Parece claro que la estructura diplomática finisecular era cuando menos precaria, al menos si nos fijamos en el número y categoría diplomática de los representantes pontificios. De entrada, no había ninguna nunciatura. Los puestos de mayor categoría eran las dos internunciaturas de Brasil y Colombia. El resto eran Delegaciones apostólicas para varios países: la de Argentina, Paraguay y Uruguay; la de Perú, Ecuador y Colombia; la de Santo Domingo, Haití y Venezuela y la de Chile (d. 1882, antes englobada en la de Perú). Con Méjico no había relaciones diplomáticas aunque sí un Visitador Apostólico entre 1896 y 1899.

Además, muchos gobiernos rompieron relaciones con la Santa Sede, pudiendo considerarse Latinoamérica como un territorio conflictivo. Argentina rompió relaciones entre 1884 y 1900; Chile entre 1882 y 1902; Colombia entre 1853 y 1881; Costa Rica entre 1884 (de facto) y 1908; Ecuador entre 1901 (de facto) y 1937 y Paraguay entre 1884 y 1900 (ó 1919, ya que en 1900 no pudo presentar credenciales), Uruguay entre 1884 (al romperlas con Argentina) y 1900 y Venezuela desde 1902 (de facto). Si añadimos que con Méjico no se consiguió establecer una relación oficial, a pesar del empeño del Papa, vemos que la red diplomática pontificia en América Latina no era la que podía esperarse en un continente católico ${ }^{13}$.

Sin embargo, los representantes pontificios jugaron un papel clave en el período como cauces de información y como transmisores de las orientaciones papales.

\footnotetext{
le visite ad limina, di visitatori pontifici e un più stretto govemo dei seminari e dell attivita della giuventúm. (TRINCHESE, STEFANO, Sviluppi missionari..., pp. 81-2.

13 «Molti dei loro Govemi non conservano affato relazioni ufficiali con la S. Sede, avendole interrotte, $O$ in tempi di politiche convulsioni, come il Messico, Costarica, il Chile, la repubblica di Honduras, o per malvolere di governanti, come l'Argentina, l'Uruguay, il Guatemala, il Paraguay. Con altri si conservano nominalmente ottimi rapporti; ma si rende difficile l'opera benefica dei partiti politici; poiché, com'é ben noto un solo Delegato Apostolico é accreditato presso i Governi dell'Equatore, del Peru e della Bolivia, un altro presso quelli di Haiti, di San Domingo e Venezuela. La Colombia ed il Brasile solamente godono del beneficio di una propria rappresentanza della S. Sede». (Sulle condizioni politico-religiose delle Repubbliche Americane del Centro e del Sud. Relazioni Generali (en adelante Sulle condizioni...), ARCHIVIO DELLA SACRA CONGREGAZIONE DEGLI AFFARI ECCLESIASTICI STRAORDINARI (en adelante AES), AMERICA, 1894, Positio (en adelante, pos.) 61, fascicolo (en adelante fas.) 6, p. 222.
}

La América y la España Contemporánea

Hispania Sacra 49 (1997) 


\section{EL PROYECTO CONTINENTAL DE LEÓN XIII}

Hasta ahora no parece que se haya estudiado si existí un proyecto global sobre Latinoamérica, a partir de la declaración de intenciones de León XIII en la carta programática diplomática de 1887, en la que manifestaba su deseo de dedicar atenciones particulares al continente. Sí se sabe ya que el Papa era muy cuidadoso en la planificación de las grandes líneas de acción que se reservaba muchas veces personalmente. Recientemente se ha descubierto en los archivos vaticanos el plan que León XIII elaboró para un replantamiento mundial de las misiones ${ }^{14}$.

No tengo noticia de algo similar para Latinoamérica, pero sí puede afirmarse que hay una línea de actuación que culmina en el Concilio plenario de 1899. Las líneas generales de actuación proceden de la conciencia -siempre desde la visión romana- de las carencias de la cristiandad americana, contempladas además desde el deseo de presencia y conquista social católica en que se concretaba a fin de siglo la acción católica.

Las directrices fundamentales de la acción vaticana podría resumirse muy brevemente: a) toda América Latina es un único continente y es claramente católico; b) la carencia fundamental es el clero, escaso e ignorante; c) se requiere por tanto aumentar, fortalecer y unificar la jerarquía para mejorar el clero y organizar a los laicos para influir intelectualemente - prensa y ensenanza- en la sociedad.

¿Sirve eso para poder hablar de un programa leoniano para América Latina? Probablemente sí. Desde luego, las carencias que acabo de señalar están muy claras para quienes, desde Roma, se encargaban de los asuntos latinoamericanos. No tenían duda de la unidad continental y ese concepto unitario de América Latina se mantuvo inflexiblemente en todo el pontificado ${ }^{15}$. Como ya hemos dicho, la Santa Sede no sólo utilizó ampliamente el término América Latina sino que contribuyó a crearla. Un ejemplo clato lo tenemos en las consultas previas al concilio plenario latinoamericano. Los episcopados de Mexi$\mathrm{co}$, Haiti' $\mathrm{y}$ Brasil se opusieron en un primer momento a incorporarse argumentando que eran diferentes por origen, lengua y tradiciones, como dirá Hai-

14 Vid. PRudhomme, ClaudE, Stratégie missionnaire du Saint-Siège sous Léon XII, 18781903: centralisation romaine et défis culturels, Ecole Française de Rome, Rome 1994.

I5 «parsi sopra un continente vastissimo ed alla estremita di un altro, od abitanti sopra isole, per la estensione di circa venti milioni di kil. q., sembrano formare una sola famiglia per comunanza spesso di origine, di linguaggio, sempre di fede, di tradizioni, di sistemi governativi. Travagliati dagli stessi mali, provati alle stesse sventure, oggi tutti, dopo lunghe guerre fratricide ed interne rivoluzioni, si sono sottratti ad ogni influenza di governi stranieri, e, divenuti autonomi, si reggono con governi popolari». (Sulle condizioni..., AES, AMERICA, 1894, Pos. 61, fas. 6, p. 221). 
tí16; por diferente nacionalidad y falta de medios, como dirán los brasileños reunidos en concilio nacional en $1890^{17}$; o por razones de oportunidad y falta de libertad política, como argumentaran los mexicanos ${ }^{18}$. En ningún caso la Santa Sede admitió que estas naciones se excluyesen del mundo latinoamericano.

Respecto al clero, no sólo aparece como una necesidad, sino que es habitual ya a fin de siglo la distinción entre clero viejo y clero nuevo. Hay por tanto un gran esfuerzo renovador: renovación de viejas órdenes religiosas —en situación crítica en Brasil-, introducción de nuevas, creación de seminarios, envío de jovenes al colegio Pío Latino Americano, todo ello con miras en la constitución de un clero local cultivado y apostólico del que pudieran salir obispos adecuados. Las referencias son abundantísimas: de hecho, puede decirse que el Concilio Plenario Latinoamericano se planteó en gran medida para unificar la acción episcopal y dar pautas claras y unitarias de comportamiento al clero.

En cuanto al tercer punto, es también claro que hay un gran interés en lanzar una acción católica americána de corte más cultural que político, que pudiese oponerse al liberalismo, al librepensamiento, al positivismo y a las sectas masónicas, los grandes males sociopolíticos de las naciones americanas, desde el punto de vista de la curia romana. Tales líneas de fuerza de la Santa Sede en América son consecuencia de su visión del continente.

\section{AMÉRICA LATINA SEGÚN LA DIPLOMACIA VATICANA}

En Roma se recibían constantes informaciones sobre la situación de la Iglesia. Unas oficiales, de los delegados apostólicos de los obispos, requeridos por algún asunto o en las visitas ad limina, y otras muchas de informadores espontáneos o interesados que enviaban a Roma todo tipo de documentación, desde relaciones de viajes a opiniones personales, pasando por recortes de prensa, folletos o denuncias. Sorprendentemente, todo se recogía, se valoraba y se estructuraba para ser utilizado en las sesiones de cardenales o expertos que debían tomar decisiones. Para nuestro caso, el conjunto más abundante y

16 Cfr. L'Arcivescovo di Porto-Principe si dichiara anchi a nome dei suffraganei contrario a prendere parte al proposto concilio, 25 giugno 1889, Sulle condizioni..., AES, AMERICA, 1894, Pos. 61, fas. 9, pp. 904-5).

17 Cfr. Atti delle conferenze dell'Episcopato Brasiliano, celebrate nella Capital di S. Paolo sotto la presidenza dell'Eccmmo e Revmmo Monsig. D. Antonio de Macedo Costa, Arcivescovo de Bahia e Primate del Brasile, Octava conferenza, 18 agosto 1890, Sulle condizioni..., AES, AMERICA, 1894, Pos. 61, fas. 7, pp. 409-10.

18 L'Arcivescovo di Messico significa il propio parere e quello di altri dieci Vecovi, negandosi di prendere parte al progettato concilio, 12 settembre 1889, Sulle condizioni..., AES, AMERICA, 1894, Pos. 61, fas. 9, pp. 906-9.

La América y la España Contemporánea Hispania Sacra 49 (1997) 
coherente de información sobre la situación de América Latina a final de siglo podemos encontrarla en la Sacra Congregazione degli Affari Ecclesiastici Straordinari, sobre todo en relación con la puesta en marcha del Concilio Plenario Latinoamericano. Interesan también la recogida en los archivos de la Secretaría de Estado, especialmente en las informaciones diplomáticas y en las Instrucciones a nuncios, así como los informes temáticos ${ }^{19}$ que Rampolla pidió a todos los representantes pontificios a fines de siglo para analizar globalmente la situación de la Iglesia en sus puntos neurálgicos: política, seminarios y clero, órdenes religiosas, prensa y acción católica.

Aquí usaré sobre todo las que se refieren al Concilio Plenario Latinoamericano, reelaborados en 1894 a base de documentos recibidos a lo largo de una década. Ellos dibujan el siguiente aguafuerte de la situación americana.

\subsection{Un continente preocupante}

La década 1888-1898 podemos abrirla con dos cartas llegadas a Roma con la intención explícita de ofrecer información sobre el conjunto del continente y proponer remedios. La más descriptiva es la de Mariano Soler, vicario general de Montevideo, escrita tras realizar un viaje por toda América Latina para recaudar fondos para el Colegio Pío Latino Americano. Escribe al Card. Laurenzi, rogándole que se interese y haga interesar al Papa por el «estado sumamente decadente del Catolicismo en América Latina ${ }^{20}$. De algún modo planteaba que la situación era peor que en los países de misión, pero el remedio más fácil:

\footnotetext{
«La mitad de los esfuerzos que se han hecho por el Oriente hubiera salvado América Latina, que se pierde por el abandono y por obra de la masonería, del liberalismo y de la propaganda protestante en muchas partes, así como por la llegada de Europa de lo más perverso e impío de cada secta [...] La Religión es perseguida en todos los aspectos, y con todos los medios, hipócritas o manifiestos, empobrecida, esclavizada, sin influencia social, y sin clero a la altura de las exigencias actuales, falto de celo y en su mayor parte corrupto. Mientras el Catolicismo florece en los Estados Unidos del Norte, donde el Clero y los fieles despliegan una energía heroica [...] en América Latina al contrario la indiferencia y la postración moral y religiosa es casi incré́ble, si no la hubiese visto con mis propios ojos.»
}

19 Los informes a que me refiero correspondientes a España son los publicados por CARCEL ORTi, VicENTE, León XII y los católicos españoles, Eunsa, Pamplona 1988. Informes semejantes se hicieron de todos los países con representación diplornática.

20 Lettera di Mariano Soler, Vicario generale di Montevideo, Roma, II-1888, ASV, Spogli, Card. Mariano Rampolla del Tindaro, Busta I, (A-D). 
La otra carta significativa de ese año es la Mariano Casanova, arzobispo de Santiago de Chile ${ }^{21}$ y también describe una dura situación para la Iglesia americana, cercada por los gobiernos y las sociedades secretas. Según él, muchos de los máximos gobernantes estaban imbuidos del espíritu del siglo, seguían las normas que suponían vigentes en Europa e imponían consecuentemente el matrimonio civil o la separación de la Iglesia y el Estado, pero reforzando el daño con el recurso al regalismo heredado de España. Casanova proponía como sistema de defensa la reunión de un concilio general americano para que las distintas iglesias dispusiesen así de unas normas de actuación comunes y de criterios doctrinales claros, hasta entonces inexistentes. Ambas cartas serán atendidas, y el análisis de la situación confirmó la alarmante situación esbozada en 1888, que exigía actuaciones claras en casi todos los países.

En 1894, se reunió la comisión de cardenales de la Sacra Congregazione degli Affari Ecclesiastici Straordinari para analizar las medidas que se podían tomar sobre la vida religiosa en América Latina. Los oficiales de Affari Ecclesiastici Straordinari prepararon un informe de 942 páginas, analizando el conjunto del continente y la situación en cada país, con un anexo de 103 documentos entre 1881 y 1893 . El documento es significativo no sólo para conocer la situación de la Iglesia latinoamericana sino también la autoconciencia institucional de la curia romana en aquel momento. No se mencionan problemas esperados --relaciones laborales, por ejemplo-, y en cambio, surgen con fuerza prevenciones políticas y culturales sobre la articulación de la sociedad que se iba perfilando ${ }^{22}$.

\subsection{Causas principales de la dificil situación de los pueblos americanos ${ }^{23}$.}

\subsubsection{Nacionalismo}

Seguan el informe, la causa principal de la triste condición moral en que se encontraban los pueblos americanos había que buscarla en el excesivo espíritu de libertad e independencia que, desde hacía medio siglo predominaba en todas las repúblicas. Las hacía celosas las unas de otras porque ninguna quería ser menos. De ahí que en muchas ocasiones, la actuación de un representante

21 Lettera di Mons. Arcivescovo di S. Giacomo del Chili al S. Padre sula convocazione di un concilio per l'America del Sud, 26 ottobre 1888, Sulle condizioni.., AES, AMERICA, 1894, Pos. 61, fas. 6, pp. 871-8.

22 Sulle condizioni..., AES, AMERICA, 1894, Pos. 61, fas, 6-9, 942 pp.

23 Sobre el tema vid. también PAZOS, ANTON M., Los problemas de la lglesia latinoamericana hace un siglo, según la documentación vaticana, en ESCUDERO, JOSÉ (ed.), Historia de la evangelización en América, Libreria Editrice Vaticana, Ciudad del Vaticano 1992, pp. 875-84 y, más desarrollado, PAZOS, ANTON M., La Iglesia en la América del IV Centenario, Editorial Mapfre, Madrid 1992. 
pontificio resultase ineficaz sólo porque residía en la capital de un estado distinto de aquel con cuyo gobierno debía tratar.

Por una parte, las naciones americanas imitaban en los aspectos negativos todo lo que se hacía en Europa, pero por otra, rechazaban hasta la más mínima sombra de influencia extranjera. Así, deseaban que los obispos fuesen nombrados entre el clero local, aunque fuese tal que no permitiese una elección adecuada. No escuchaban ninguna instrucción ni norma, aunque viniese de la Santa Sede, si no estaban convencidos de que no lesionaba para nada su independencia. En cambio, se rendían con facilidad a quien reconociese la superioridad de cada nación frente a las otras y parangonase su desarrollo como parejo a las naciones europeas.

\subsubsection{Frecuente uso del patronato}

Este rechazo ante toda influencia exterior hacía que los gobernantes, incluso aquellos que estaban en buena relación con la Iglesia intentasen evitar toda ingerencia de Roma y recurriesen con tenacidad hasta el exceso, a veces llegando al ridículo, a hacer uso del patronato. Un ejemplo eran los nombramientos eclesiásticos, que no se limitaban a los obispos y dignidades, sino hasta los canónigos honorarios y los encargados del servicio material de la Iglesia. De hecho, se dice, los presidentes se consideraban como Vicarios Apostólicos en todas las provisiones eclesiásticas. En la misma línea estaba la oposición de todos estos gobemantes a la celebracion de sínodos, si no iban precedidos de la autorización del ministro o presidente, argumentando que era un derecho heredado de la corona española.

En este esquema ya rancio de patronato, los delegados apostólicos eran difícilmente asimilables. Son muy frecuentes los informes de delegados apostólicos, manifestando la desconfianza con que era recibido todo representante de la Santa Sede. «Gobierno, obispos, clero, - -se dice-m todos fantasean, con mal celada curiosidad, sobre las instrucciones, sobre el verdadero objeto de su misión, suponiendole siempre alguno oculto. Sólo cuando, al cabo de varios meses, se han convencido de la lealtad y honradas intenciones del delegado, fácilmente se tornan benévolos y, si les sabe aconsejar, se confían con franqueza.» Situación más difícil aún si tenemos en cuenta el papel que Leớn XIII pretendía para los nuncios en la construcción de la cristiandad.

\subsubsection{Libertad de expresión}

El informe señala como una consecuencia más del afan de libertad tan típicamente latinoamericano la falta de referencias morales en la enseñanza y en la 
educación. Se llegaba hasta pretender que un profesor no debía tener ninguna restricción, ningún límite en la enseñanza sino su propio talento. En consecuencia, se enseñaba todo el materialismo, el deísmo, el panteísmo desde las cátedras de las instituciones públicas: todo el esfuerzo se ponía en promover la enseñanza, no en cuidar sus contenidos. Que un director de escuela fuese protestante, ateo, católico, o inmoral nadie lo investigaba: bastaba con que fuese hombre considerado docto y que supiese mantener su cargo con prestigio. Incluso los religiosos y las monjas -escasos por otra parte- que habían abierto escuelas o colegios estaban obligadas a ser muy tolerantes a causa de tales prejuicios, y tenían que permitir a los alumnos la libertad de frecuentar las familias y, a veces, de asitir a las clases, de los profesores oficiales.

A la libertad de enseñanza habría que añadir los daños de una inmoderada libertad de prensa, para tener un cuadro bastante exacto del estado deplorable en que se encontraban los pueblos americanos a causa del desmedido amor a la libertad nacional y personal. El informe destaca que la libertad de prensa en América Latina se entendía en un sentido más amplio que en Italia y en Francia.

\subsubsection{Excepcional influencia de la inmigración europea}

Los inmigrantes podían considerarse desde dos puntos de vista. Uno activo, podríamos decir, ya que con frecuencia ejercían una influencia determinante en el desarrollo de la vida social en muchas de aquellas regiones. El otro podríamos llamarlo pasivo, ya que aún más frecuentemente, eran ellos los que tenían mayores necesidades, dignas de ser estudiadas por la Santa Sede. Este me parece que es el problema social católico fundamental para Latinoamérica en el cambio de siglo, al que no se pudo hacer frente con mucha eficacia. En los años noventa, desde luego, se podía «afirmar con certeza que los inmigrantes y los extranjeros eran causa de escándalo para los naturales». Si se exceptuaban los agricultores, que emigraron con sus familias, empujados sólo por la necesidad, los demás eran calificados con gran dureza como «gentes perdidas».

El problema se veía como acuciante, ya que incluso los mismos agricultores, si no conseguían organizarse en núcleos fuertes, y no recibían ayuda espiritual, no tardaban en volverse cuando menos indiferentes en lo tocante a la religión: algunos llegan a convencerse de que en América no están obligados a aquellas prácticas de piedad a las que eran tan asiduos en la propia patria. Era frecuente escuchar en confesión esta respuesta de boca de un campesino emigrado: «Yo en casa era muy cumplidor, pero ahora bien sabe Dios que estoy en América.»

Para los países americanos esta inmigración era deseada y resultaba ventajosa para los intereses materiales, pero para la religión — se afirma taxativa- 
mente- era siempre perjudicial. No parecía fácil de resolver ya que el mismo hecho de emigrar, tal como lo hacían los latinos, impedía trasladar a América las estructuras sociales de origen. Para el informe resultaba grave que hombres de todas las naciones, de las sensibilidades más dispares, de todas las religiones, cismáticos, protestantes, hebreos, católicos, ateos, se uniesen formando como una misma tribu. El panorama conjunto era francamente negativo: con las personas honradas se mezclaban fugitivos de la justicia de los tribunales europeos. La blasfemia no se conocería sin el ejemplo de los europeos. La inmoralidad en las costumbres, a la que se abandonaban con gran facilidad los americanos, se volvía más desenfrenada por el contacto con los extranjeros, los cuales, sintiéndose desconocidos, se lanzaban a todos los excesos.

Un aspecto peculiar de las oleadas migratorias finiseculares, que se reflejaba muy duramente en la pastoral y en el derecho canónico eran los matrimonios ultramarinos. El informe llega a afirmar que el concubinato ${ }^{24}$ había llegado a generalizarse tanto en algunos países que casi no causa a escándalo; los emigrados, bien por la dificultad de conseguir los documentos necesarios para contraer regularmente matrimonio, bien porque obligados ya por otros vínculos en la patria de origen, preferían realizar uniones ilícitas y condenables, aunque simulando matrimonio, para evitar un posible rechazo social.

Esto creó bastantes problemas prácticos y denuncias - tanto por parte de los cónyuges europeos como de los americanos-, en los casos en que se descubría la bigamia. La Santa Sede tuvo que dirigir una circular en 1893 a todos los ordinarios de América Latina para que se cerciorasen del estado libre de los inmigrantes que solicitaban matrimonio religioso.

El problema migratorio, sin embargo, no se reducía a comportamientos prácticos por muy graves que fuesen. Resultaban también especialmente perniciosas las ideas y teorías que difundían entre el pueblo y en los centros obreros. «No hay error ni teoría -se dice-, por impía que sea, de la que no intenten presentarse como maestros. Y su labor resulta tanto más perniciosa cuanto se desarrolla entre un pueblo tan deseoso de progreso como ignorante, que no conoce ni siquiera las verdades más elementales en materia religiosa.»

De hecho, el informe destacaba que era entre los inmigrantes donde encontraban sus mejores colaboradores los partidos subversivos y antirreligiosos.

24 Aunque aquí se habla de concubinato o unión extramarital de facto, hay que tener en cuenta que el término es equívoco, ya que también el matrimonio civil, sin matrimonio religioso es considerado canónicamente como concubinato, y así se entiende en la documentación vaticana de la época. 


\subsubsection{Liberalismo y masonería}

Esencialmente, las ideas liberales y sus medios se presentan en América con las mismas características que en Europa: «Las asociaciones condenadas por la Santa Sede, aliadas con el liberalismo producen incalculables daños [...] La táctica de guerra es la misma: se propagan todo tipo de errores con el pretexto de la libertad del pensamiento; se divulgan las más insensatas acusaciones contra la Iglesia, apelando a la objetividad y veracidad de la historia: en fin, los mismos fines con los mismos medios.»

Los efectos, sin embargo, eran mucho más negativos que en Europa, precisamente por la falta de estructuración social y de desarticulación de la Iglesia: «Cuando los apóstoles del liberalismo - los cuales casi siempre confiesan ser católicos- y los sectarios llegan al poder, no encuentran ninguna resistencia en la sociedad, por ser tan escasos y aíslados los centros de la acción católica entre los laicos, sean nativos o inmigrados.»

La masonería es presentada como omnipresente -al menos en ambientes cultivados- y muy tolerada socialmente. «La masonería - se dice- está en la mayor parte de las ciudades más cultas y domina soberana en las asambleas legislativas. Casi siempre es un Estado dentro del Estado y no siente necesidad de ocultarse. Tiene públicas y espléndidas logias; anuncia sus reuniones en los periódicos; en ocasiones publica sus deliberaciones; amonesta a los católicos más celosos; intimida a los ministros y a los parlamentarios.» Sin embargo, se ofrece una nota peculiar, que la diferencia de la europea, y es su conexión con el espíritu sincretista, tan presente en muchos lugares de América. Los delegados apostólicos presentan con frecuencia una masonería que «para afirmarse aún más hacía manifestaciones de religiosidad, como en Santo Domingo hace pocos años, donde se edifić́ una capilla a San Juan Bautista a expensas de la logia masonica, y fue bendecida por un sacerdote que ostentaba las insignias de su grado ritual. Podía decirse que la festividad de San Juan Bautista se celebraba en muchísimos países a cargo de la masonería».

\subsubsection{Legislación anticatólica}

La masonería contribuía además mucho a crear inestabilidad —ya crónicaen los gobiernos. Apenas un partido llegaba al poder, los masones empezaban a favorecer a la oposición, y así obtenían favores de los que gobernaban, que temían ser abatidos, y promesas de los que aspiraban a gobernar, que después eran forzados a cumplirlas, al menos en parte, cuando alcanzan el poder.

Esa agitación de los partidos no era la menor causa de la pésima legislación vigente en la casi totalidad de las repúblicas americanas, porque todo el que 
llegaba al poder no dejaba de aportar su innovación, casi siempre a peor, en las leyes en uso. De todos modos, el mismo carácter personalista y provisional de la vida pública hacía que la mala legislación no siempre fuese perjudicial: «Como las leyes son aprobadas para complacer a personas o partidos - se dice - con la misma facilidad dejan de aplicarse o incluso llega a olvidarse que existen.»

\subsubsection{Clero secular y regular}

En la Santa Sede se consideraba que «el único que podría hacer más llevadera la dura condición de la vida cristiana era el clero. Y en alguna ocasión, en que se había conseguido oponer a los planteamientos antirreligiosos una acción conjunta y enérgica de los obispos, se habían conseguido buenos resultados. Pero el clero, desgraciadamente, casi nunca podía ser un elemento corrector de tantos males». En general la visión del clero local es muy negativa, aunque empieza ya a notarse el esfuerzo de renovación finisecular y puede - aunque de modo muy elemental aún - empezar a hablarse ya de clero nuevo.

Los obispos, en general, especialmente los elegidos en los últimos años, tenían cualidades y celo, pero - se dice citando un informe del cardenal Di Pietro de 1881- «son como capitanes con poco soldados, y éstos, perezosos, sin prudencia y sin disciplina».

El informe abunda en esa opinión: "La nota específica, es doloroso decirlo, del clero secular, es la insuficiencia, en el más amplio sentido de la palabra: el celo y la buena conducta moral son las cualidades que más escasean. La falta de candidatos obliga a los obispos a confiar las parroquias a personas que no han concluido sus estudios, no han sido educadas en el espíritu de sacrificio, no conocen sus deberes, y con frecuencia son muy jóvenes y se ven obligados a vivir en una sociedad estragada. ¿Habría que sorprenderse si fuesen arrastrados por el torbellino de las pasiones y los errores?»

De ahí que fuesen rarísimas excepciones los párrocos que predicasen el Evangelio y enseñasen el catecismo al pueblo. En consecuencia la fe, aunque persistía en las masas, languidecía cada vez más; y las misiones populares que enviaban los obispos de tiempo en tiempo no podían producir sino efectos momentáneos, que se esfumaban apenas marchaban los misioneros. Por si fuera poco, los sacerdotes inmigrados colmaban toda desventura posible. Salvo pocas excepciones iban a América con el único deseo de enriquecerse y actuaban en consonancia con este objetivo. Era una vieja batalla. En 1886 la S. C. del Concilio había dictado ya varias disposiciones contra ellos sin éxito. En 1890 se dispuso que los obispos americanos procedieran sumarísimamente 
contra los sacerdotes delincuentes, y se prohibió a los obispos italianos autorizar a sus sacerdotes a pasar a diócesis americanas.

La vida privada del clero no resulta tampoco muy bien parada: «No puede considerarse exageración -mantiene la ponencia- que el concubinato sea algo natural en la vida de muchos eclesiásticos, que mantienen públicamente relaciones ilícitas. En algunas parroquias se conoce y se trata, sin que cause escándalo, a la familia del párroco.»

Los religiosos indígenas no resultaban mejores: eran poquísimos y sin disciplina. De religiosos no tenían sino el nombre y, en ocasiones, el hábito. Aquí, como en otros ámbitos de la vida religiosa, las persecuciones del siglo habían posibilitado recrear la institución: "Afortunadamente - se dice crudamente - quedan pocos, las continuas leyes desamortizadoras los han dispersado y pronto se podrá decir que ya no existen. Y los pocos supervivientes, no quieren depender, o no dependen de hecho, de los superiores generales de las respectivas órdenes.» Sólo medidas excepcionales podrían insuflar en tales larvas de comunidades religiosas un nuevo vigor y conducirlas a la observancia, pero esas medidas tendrían que enfrentarse con la resistencia, seguramente insuperable, de los religiosos actuales.

Pero el problema no eran los religiosos, sino los nativos. La cara de la moneda son los religiosos europeos llegados a América. Contrastan tanto con el clero americano como con los seculares europeos. De hecho la Santa Sede consideraba que «el único grupo del que se podía esperar mejora y al que había que atribuír lo poco de bueno que se conserva entre aquellos desgraciados pueblos era el de los religiosos europeos, tanto hombres como mujeres, que allí se habían establecido.

La fundación de un convento o un colegios con religiosos europeos mejoraba notablemente la vida religiosa de una población. "Resulta evidente -se insiste- la transformación que se produce en la moral pública y en el sistema educativo nada más llegar un grupo de estos benefactores a una ciudad o una parroquia. Con los colegios, con las escuelas, con las misiones frecuentes, con la práctica de la predicación y la administración de los sacramentos y, sobre todo, con las conversaciones privadas y con su edificante conducta, producen efectos sorprendentes. Parece como si la gracia del Señor fecundase sus trabajos de un modo admirable». Bastaba con que los jesuitas, los salesianos u otros regulares abriesen una casa de educación, tomasen la dirección de un colegio o de una iglesia, para que inmediatamente el favor de todo el pueblo, sobre todo de las clases mejores se volcase con ellos. Los capuchinos y los lazaristas eran solicitadísimos, los primeros especiamente en las misiones y en las parroquias rurales. 
Entre las religiosas destacaban las Hermanitas de la Caridad, con una excelente labor en hospitales, en asilos, en orfelinatos y en escuelas, donde actuaban --se dice- «como verdaderos apóstoles de la religión», contando además con un absoluto apoyo social.

\subsubsection{Seminarios}

Un terreno clave de esa influencia positiva de los religiosos eran los seminarios. Casi todas las diócesis tenían sus seminarios, pero desgraciadamente - se valora en el informe- dejaban mucho que desear en cuanto a instrucción, disciplina y piedad. Sólo en aquellos en que la dirección estaba confiada a los jesuitas y lazaristas se apreciaba tal mejora que hacía suponer lo conveniente que sería aumentar su número.

Se veía como muy conveniente un plan especial para mejorar los seminarios latinoamericanos, pero analizando cada nación por separado y viendo sus posibilidades. Este es un aspecto esencial para la creación del clero nuevo que ya hemos mencionado. Y el informe no deja de señalar en esta línea que «los obispos de aquellas regiones, especialmente los de nombramiento reciente, habíann comprendido bien la necesidad de establecer seminarios adecuados y habían reconocido lealmente la pésima organización de todos los existentes. Algunos incluso habían trabajado ya mucho en este intento». Para poner en marcha un plan global se esperaba utilizar las informaciones sobre seminarios pedidos a todos los representantes pontificios por el Secretario de Estado en $1891^{25}$.

Por último se recordaba el bien que se obtenía de la existencia del Colegio Pío Latino Americano del Sur en Roma. Aunque no bastaba para cubrir todas las necesidades de las dícesis resultaba un instrumento clave para mantener en aquel clero el espíritu eclesiástico y el amor a la Santa Sede. Se había hecho una propuesta de ampliarlo a favor del Brasil pero hasta ahora no se ha conseguido.

Hasta aquí la valoración de la situación americana en los ámbitos de gobierno romanos, especialmente en aquellos de los que dependía la actuación pontifica sobre el continente. Tales valoraciones las utilizarán en esos años los cardenales miembros de la comisión promotora del concilio plenario latinoamericano, todos ellos expertos en asuntos iberoamericanos y muy próximos a

25 En esta línea resultará muy útil -se dice- la información enviada por los representantes pontificios sobre seminarios y órdenes religiosas solicitada con carta de 30 de enero de $1891 \mathrm{n} .365$ y del 1 de febrero de 1892 n. 5617. (Sulle condizioni.... AES, AMERICA, 1894, Pos. 61, fas. 6, p. 22). 
León XIII ${ }^{26}$. Hay que suponer que ésta era la visión que se aceptaba en el Vaticano si tales cardenales la admitían. Lógicamente, cada uno de los países era valorado independientemente, llegando en ocasiones a los pequeños detalles. No es posible recogerlos ahora, aunque puede interesar pararnos algo más en el área antillana, que presumiblemente coincidirá más en su situación con Cuba y Puerto Rico que otros territorios mas diversos por clima, raza y costumbres.

\section{LA IGLESIA EN EL ÁREA CARIBEÑA A FINES DE SIGLO}

Haití y Santo Domingo son los territorios sobre los que se recibía información diplomática. El resto de las Antillas carecían de jerarquía católica, de representación diplomática o eran colonias. Para Haití y Santo Domingo disponemos de varios informes finiseculares que ofrecen un panorama de los territorios caribeños que podría considerarse crítico. Baste mencionar el hecho excepcional de que el gobierno diocesano tuvo que ser asumido por el representante pontificio, nombrado al mismo tiempo arzobispo local ${ }^{27}$.

Los informes sobre ambos territorios son muy negativos con respecto a gobiemo y clero, y más favorables - con matices - respecto a las buenas disposiciones -que no costumbres- del pueblo.

\subsection{República Dominicana}

La historia religiosa de la diócesis primada de América se presenta muy dañada a final de siglo. En 1870 la Santa Sede había enviado al franciscano Leopoldo Santaché D'Acquasanta desde Constantinopla a Santo Domingo con un objetivo visible: fundar un convento franciscano en la isla y otro secreto: obtener información exacta de la situación local, especialmente sobre el clero, para

26 Los cardenales que estudiaron en 1894 la situación americana y propusieron a León XIII, entre otras actuaciones, la reunión de un concitio especial para hacer frente a los problemas americanos fueron Serafino Vannutelli, delegado apostólico en el Ecuador entre 1869 y 1877 , y el candidato alternativo de León XIII para secretario de Estado cuando nombró a Rampolla; Vincenzo Vannuteli (Internuncio en Brasil en 1883, sin tomar posesión y nuncio en Portugal de 1883 a 1891); Angelo Di Pietro (Delegado Apostólico en Argentina, Paraguay y Uruguay entre 1877-1879, Internuncio en Brasil de de 1879 a 1882 y Nuncio en España de 1887 a 1893); Luis Galimberti (Secretario de la Congregación de AES entre 1886 1887) y Mariano Rampolla (Nuncio en España entre 1882 y 1887).

27 El Delegado apostólico, Giulio Tonti (nombrado en agosto de 1892) asumió las funciones de Adninistrador apostólico ad nutum S. Sedis de la Archidiócesis de Puerto Príncipe desde 1893 y fue nombrado Arzobispo de Puerto Príncipe en 1894 (Cfr. DE MARCHI, GiUSEPPE, Le Nunziature Apostoliche..., p. 140). 
proveer al nombramiento de obispo ${ }^{28}$. El gobierno, incitado por el vicario general, le negó la posibilidad de establecer el convento no sólo en la iglesia desamortizada que pedía - ya que había sido cedida como sede a la logia masónica de rito escocés ${ }^{29}$ - sino en ningún otro local. El fracaso de esta iniciativa pudo haber influido en su informe que resulta bastante negativo. La diócesis, con 250.000 fieles y 33 parroquias tenía únicamente 28 sacerdotes, de ellos 16 indígenas carentes de los conocimientos más elementales de las ciencias eclesiáticas. No había seminario. La connivencia con la masonería era general y varios sacerdotes eran masones. Por otra parte, ésta era un actitud aceptada por el pueblo que consideraba a los masones como benefactores y veía la tolerancia del clero con ellos como caridad cristiana. Aunque no todo el clero era escandaloso ni favorable a la masonería, todos sin excepción estaban involucrados en la política, la mayoría partidarios del ex presidente Cabral, cuyo candidato -que llegaría a presidente-- «es el célebre francmasón don Fernando Meriño».

Las leyes iban en contra del precepto constitucional que establecía la religión católica como oficial: libertad de prensa, abolición del fuero eclesiástico, prohibición de fundaciones, supuesto derecho de elección episcopal, establecimiento del exequátur presidencial, etc.

Las clases bajas de la población eran religiosas, amantes del catolicismo y unidas a Roma, pero ignorantísimas. Frecuentaban mucho la iglesia, aunque la confesión y comunión habían quedado para las mujeres. Muchos viejos y casi todos los jóvenes vivían en concubinato, a lo que contribuía la pobreza, por no tener dinero para pagar las tasas matrimoniales que exigía el clero.

«El abuso del baile llamado de la Bámbula los tiene tan ocupados que gastan en él toda la noche y parte del día [...] son mentirosos y no aman el trabajo. Sin embargo todas estas gentes frecuentan la iglesia, van a Misa y practican otras obras piadosas. No se puede ir por la calle sin que se acerquen a pedir la bendicion y traen a sus ninos para que se los bendiga», concluye con perplejidad el P. Santaché su análisis de la religión popular haitiana.

Las clases altas tenían los mismos vicios pero eran menos practicantes. Las mismas cofradías católicas participaban en los banquetes masónicos y las logias iban sustituyendo a las Iglesias. En cambio no había ningún dominicano que fuese protestante. El millar aproximado que había en la isla era contingente extranjero, aunque iba en aumento.

28 Su informe en Relazione fatta alla Santa Sede dal P. Leopoldo Santaché d'Acquasanta Missionario Apastolico dei Minori Riformati sulla Condizione Religiosa della Repubblica di San Domingo nelle grandi Antille, Giugno 1870, AES, AMERICA, 1894, Pos. 61, fas. 8, pp. 534-604.

29 lbid., p. 548. 
La atención pastoral era mínima. En muchas iglesias eran las mujeres las que se encargaban de abrir e incluso de mantener alguna forma de culto. En la capital haría falta al menos refundar un convento - de los cinco que existían antes-y una docena más de sacerdotes. En Santiago de los Caballeros no bastaría con seis sacerdotes y había dos y así en otros 15 pueblos. Algunos niños morían $\sin$ bautismo o lo recibían a los 10 ó 12 años. Nueve parroquias estaban desatendidas. El seminario se había unido hacía años a la enseñanza oficial y los responsables - laicos y eclesiásticos - eran masones. El primer rector había apostatado y se había casado civilmente. El actual vicerrector -laico- era un «encarnizado volteriano». La enseñanza que se impartía estaba llena de errores: era favorable al matrimonio de los sacerdotes, al divorcio y con errores de fe. La confesión y la comunión se practicaban una vez al año. Afortunadamente, concluye, se había cerrado hacía tiempo y era mejor que siguiese así. La única solución que se veía a los males dominicanos era el nombramiento de un arzobispo neutral en materia política - algo casi imposible entre los nativosauxiliado por nuevos misioneros venidos de fuera.

De hecho no se hizo así. El arzobispo que se nombró era precisamente el mencionado Meriño, acusado de francmasón pero uno de los hombres más influyentes del país, que había sido presidente de la Asamblea, Rector de la Universidad, presidente de la República y embajador en Francia. De ahí que los informes posteriores no se aparten mucho de lo que se recogía en 1870. En $1887^{30}$ se mantenía la situación a grandes rasgos, pero con matices. El nuevo presidente de la República había sido ministro de Interior cuando el arzobispo Meriño era presidente, por lo que el gobiemo estaba en la «mejores relaciones» con la Iglesia. No había concordato, pero el delegado lo atribuía a la falta de madurez del país, que podía considerarse aún en formación. La prensa católica se reducía al boletín eclesiástico. Del seminario decía textualmente: «¿Qué puedo decir de bien cuando todo el mundo habla mal? Los pocos alumnos que tiene no dan ninguna esperanza. El mismo clero está espantado del porvenir de esta iglesia.» La encíclica Humanum genus, contra la masonería, no se había difundido por interés del propio Mons. Meriño ${ }^{31}$, que era entonces administrador apostólico.

\footnotetext{
30 Rapporto di Mons. di Milia intorno alle condizioni politico-religiose di S. Domingo, 23 Ottobre 1887, AES, AMERICA, 1894, Pos. 61, fas. 8, pp. 606-13.

31 Hay que tener presente que la historiografia al uso suele presentar a Mons. Fernando Meriño más como un padre de la patria y uno de los grandes hombres de la Iglesia dominicana que con los tintes que le dan los informes diplomáticos vaticanos. En una reciente Storia della Chiesa italiana se le presenta como «un uomo que uni a insolite dote oratorie anche un'abile amministrazione: di lui hanno scritto que nessun altro presidente aveva mai gobernato in modo così energico e deciso. Una stima ancor maggiore si guadagnd como vescovo di Santo Domingo» (HENKEL, WILLI, La Chiesa in

La América y la Esparia Contemporánea Hispania Sacra 49 (1997)
} 
En un informe posterior ${ }^{32}$ se insiste en presentar el seminario como «lugar de corrupción ${ }^{33}$ y a las únicas monjas de la isla, las Hermanas de las Ancianas, casi todas de Cuba, «espantadas ante la idea de confiar sus conciencias a sacerdotes formados en la calle».

En cambio, la masonería se consideraba en retroceso, con ascendiente sólo entre la juventud -especialmente a través de la Escuela Normal- pero abandonada ya por la generación adulta. «La encíclica Humanum genus había sacudido los espíritus serios. Sin embargo el clero no había hecho nada para manifestar los peligros de tan peligrosa secta.» El pueblo seguía viéndose como muy dado a las devociones tradicionales, especialmente las heredadas de los españoles. El delegado apostólico no veía otra solución que ofrecer al arzobispo un cargo diplomático pontificio - sugería Chile-para alejarlo e intentar hacer frente a una situación que parecía desesperada. La situacion no varió hasta la desaparición de mons. Meriño, que fue sustituído por el propio delegado apostólico.

La Santa Sede solicitó y recibió en el año 1896 varios informes sobre la acción pública de los católicos ${ }^{34}$, la prensa ${ }^{35}$ y la legislación ${ }^{36}$ en la isla, en los que se trasluce una cierta mejora, sin variar, lógicamente las líneas generales. La relaciones con el poder político no planteaban contenciosos difíciles. La nueva constitución de 1887 insistía, como era habitual en América Latina en el patronato y en la consabida exigencia del matrimonio civil previo al canónico, pero ya en 1889 se había establecido que los católicos lo realizasen obligatoriamente en el plazo de veinticuatro horas tras el civil. También el gobierno se hacía cargo - segun acuerdo de 1881- del pago del capítulo catedralicio, aunque de hecho no estaba constituido, bien porque el gobierno nunca había pagado los mil escudos mensuales acordados, bien por falta de clero. Las quejas por esta escasez continuaban. Las $\mathbf{4 5}$ parroquias de la nación estaban casi todas cubiertas, pero seguía siendo «general el lamento de la insuficiencia del

America Latina..., p. 537). Realmente casi no parece verosímil que valoraciones tan contradictorias se refieran a la misma persona.

32 Relazione di Mons di Milia intorno alle attuali condizioni della Republica di San Domingo, AES, AMERICA, 1894, Pos. 61, fas. 8, pp. 61425.

33 bid., p. 620.

34 Relazione sull'Azione del laicato Cattolico nelle Repubbliche di Haiti, Venezuela e di S. Domingo, nell'ordine pubblico, amministrativo e politico, compilata da Don Gualtieri, Segretario del Delegato Apostolico, Mons Giulio Tonti, AES, Haiti, 1896, n. 98, fas. 24.

35 Relazione sulle condizoni det gionalismo cattolico e liberale nelle Repubbliche di Haiti, $S$. Domingo e Venzuela compilata da Don Domenico Gualtieri, Segretario del Delegato Apostolico, Mons Giulio Tonti, AES, Haiti, 1896, n. 97, fas. 24.

36 Relazione sulla legislazione Civile-Ecclesiastica vigente nelle Repubbliche di Haiti e di $S$. Domingo, compilata da Don Domenico Gualtieri, Segretario del Delegato Apostolico, Mons Giulio Tonti, AES, Haiti, 1896, n. 94 , fas. 15 . 
número de eclesiásticos para las necesidades siempre crecientes de una población de casi 400.000 habitantes, diseminados en un vastísimo territorio ${ }^{37}$, además de «por su mala formación». Para colmo, aunque legalmente no había ninguna oposición a la existencia de órdenes religiosas, en toda la república «sólo había un instituto diocesano de mujeres, llamadas Hermanas de los Pobres, compuesto de unas quince religiosas». Respecto a la prensa católica, se seguía con el boletín eclesiástico y ningún otro periódico, sin esperanzas de conseguirlo en breve ya que no había director posible, ni clérigo ni laico. No era esepcialmente preocupante, con todo, ya que los periódicos liberales -unos quince - «no tenían por sistema actitudes hostiles a la Iglesia [...] y no eran contrarios a publicar artículos sobre asuntos religiosos ${ }^{38}$. Lo mismo podía decirse sobre la actuación política de los católicos. De hecho, las tendencias gubernativas eran «de plena armonía con el sentimiento católico de la nación [...y] si a la excelente legislación correspondiese una exacta aplicación práctica [...] no habría ninguna queja que presentar contra el gobierno» ${ }^{39}$.

En todo caso, no era muy preocupante que no hubiese partidos políticos o acción católica, ya que el sistema de gobierno de Ulises Heureaux los había eliminado, hasta el punto de comentar el informe que mientras el general fuese presidente «nadie que apreciase su propia vida osaría ponerse al frente de un nuevo partido político ${ }^{40}$. En el fondo, igual que la falta de apoyo económico del Estado era consecuencia de una hacienda en bancarrota, la vida política estaba sin constituir. Los católicos, ni siquiera eran conscientes de sus obligaciones sociales. «Antes de poder ver a éstos elevarse hasta la comprensión de los valores sociales será necesario el paso de los años y un incesante trabajo de evangelización», que desgraciadamente no era capaz de realizar el clero, se concluía. Lógicamente no había en todo el país ninguna asociación católica con esos fines. Todas las existentes «tenían carácter única y exclusivamente religioso».

\subsection{Haití}

La situación de Haití va a resultar tan diferente de la República Dominicana como eran las dos partes de la isla en su política, lengua y raza.

Haití era una sorprendente organización étnica y religiosa en medio de América Latina. El clero, casi todo secular, era excelente, pero no autóctono:

${ }^{37}$ Relazione sulla legislazione..., AES, Haiti, 1896, n. 94, fas. 15, f. 19v.

${ }^{38}$ Relazione sulle condizioni del giornalismo..., AES, Haiti, 1896, n. 97, fas. 24, f. 18v.

39 Relazione sull Azione del laicato..., AES, Haiti, 1896, n. 98, fas. 24, ff. 30r-v.

40 Ibid., f. 38 .

La América y la Espafia Contemporánea

Hispania Sacra 49 (1997) 
provenía de Francia donde se había establecido un seminario especial en Bretaña para formarlo ${ }^{41}$. De algún modo era misionero en su formación y origen y también en su labor, ya que trabajaba -se dice-con admirable «espíritu de abnegación y sacrificio desde hace más de treinta años para extirpar de entre estas poblaciones de origen africano las degradantes prácticas del fetichismo e implantar y propagar la religión» ${ }^{42}$. Existían además, varias congregaciones, masculinas -Padres del Espíritu Santo, Hermanos de la Enseñanza Cristiana de Ploërme - y femeninas, como las religiosas de San José de Cluny y de la Sabiduría. De facto era una iglesia extranjera y el esfuerzo de la Santa Sede en los años noventa para implantar un clero indígena fue una de las mayores dificultades que tuvo Roma en Haiti ${ }^{43}$.

No sólo era francés el clero. La clase dirigente se formaba en Francia, y el informe la presentaba como «ávida consumidora de los libros más perversos que allí se publicaban tanto de doctrina como de moral» ${ }^{44}$. De hecho, los esquemas públicos eran calco de la Franciá revolucionaria. La constitución era atea, aunque moderada por el concordato de 1862, por el que se reconocía la religión católica como la de la mayoría de los haitianos y se ayudaba a la Iglesia. En estos momentos tal acuerdo, muy atacado al firmarse ya había logrado instalarse sólidamente en las costumbres del país. Pero se subvencionaba también a otras religiones, estaba absolutamente prohibido el matrimonio religioso sin haberse realizado antes el civil, y el divorcio no sólo estaba admitido sino que «se consideraba una de las libertades heredadas de la Revolución francesa». El delegado apostólico lo veía como especialmente preocupante en «un país donde el sentimiento de familia casi no se conocía» ${ }^{45}$.

La tolerancia aparecía también en la escuela: los maestros no tenían obligación de enseñar la doctrina católica, aunque debía permitir al párroco que la impartiese. Un conflicto, relacionado con la tolerancia en la enseñanza, era el nombramiento de inspectores protestantes para escuelas de alumnado católico. Entramos así en otra característica diferencial de Haití: la presencia del protestantismo, que siempre había sido «halagado» por el gobierno, aunque el obispo esperaba que el presidente «no tardase en rechazar las intrigantes influencia de los protestantes». Con todo, no sólo presionaban en el gobierno o

41 Primero se había establecido en Pontchâteaux, regido por los Monfortinos. En 1893 fue transferido al clero secular. Del seminario de Pontchateaux habian salido en setenta afios 520 sacerdotes, cifra muy superior a casi todas las naciones latinoamericanas, de más población (cfr. HENKEL, WLLI, La Chiesa in America Latina..., p. 434.

42 Relazione sulla legislaziones Civile-Ecclesiastica..., AES, Haiti, 1896, n. 94, fas. 15, f. 4. 314-6.

43 Algo más desarrollado este conflicto en PAZOS, ANTON M., La Iglesia en la América..., pp.

44 Relazione sulle condizioni del giornalismo..., AES, Haití, 1896, n. 97, fas. 24, f. 13.

${ }^{45}$ Relazione sulla legislazione..., AES, Haití, 1896, n. 94, fas. 15, f. 8v. 
la política sino en la calle. La tradicional enemiga eclesiástica contra la prensa liberal cedía en Haití frente a «las llamadas conferencias que de tiempo en tiempo publicaban las sectas protestantes y que difundían por todas partes de Haití a manos llenas». Si se había planteado la necesidad de prensa católica, en parte era para hacer frente a los protestantes, ya que el periodismo haitano era tan malo que «ni siquiera los periódicos liberales tenían ningún valor».

El combate periodístico tenía sentido misionero, no político. Se veía como la única manera de llegar a «las nueve décimas partes de los hombres [que] estaban fuera de la acción directa del ministerio sacerdotal [...pues] para la gran mayoría de los haitianos no existían ni misas, ni predicaciones, ni prácticas religiosas: «en una palabra - se concluía con dureza- podian considerarse como paganos bautizados ${ }^{46}$. Un periódico se veía como buen punto de partida para después organizar asociaciones de las que «en Haití apenas se tenía idea». Algo se estaba haciendo. El obispo de Cap-Haïtien había lanzado «La Croix de Cap-Haïtien», pero llevaba unos meses de vida, y no era muy seguro que durase. De hecho el problema para lanzar un buen periódico volvía a ser la escasez de personas: resultaba difícil encontrar un director que fuese constante y no entrase en política.

De todos modos, si en la República Dominicana no había partidos, los que había en Haití tampoco denotaban una vida política muy elaborada. Las opiniones políticas saltaban a la vista: los negros eran del partido nacional y los mulatos del liberal. No había espacio para un partido católico, aunque sí para otras organizaciones con finalidad social moralizante. Así había empezado a hacerse en Puerto Príncipe, donde el presidente del «Círculo católico», asociación lánguida y ređucida, le había añadido una «Oeuvre morale», precisamente para la mejora moral de la sociedad mediante bibliotecas y conferencias. Con todo, estaba en sus comienzos y no había que esperar resultados inmediatos de la acción católica en Haití. Se presumía que «tardaría más en dar frutos que en otros lugares por los malos instintos morales y la fuerte inclinación al fetichismo que esta población había heredado de la sangre africana que llevaban en las venas ${ }^{47}$. El carácter de los nativos, el apegamiento al hecho diferencial del nacionalismo nacido de la revolución francesa y la certeza de que «la parte dirigente de la nación, especialmente los legisladores, estaban casi todos afiliados a la masonería ${ }^{48}$ así lo hacía esperar.

Como se ve, el Caribe no era precisamente una tierra de promisión para la Iglesia latinoamericana. Cuba y Puerto Rico, por clima y población _-_exceptuando los españoles de la península - están en ese entorno. Los pocos datos de

46 Relazione sulle condizioni del giornalismo.... AES, Haití, 1896, n. 97, fas. 24, ff. 12v-13.

47 Relazione sull'Azione del laicato..., AES, Haiti, 1896, n. 98, fas. 24, f. 41.

48 Relazione sulla legislazione..., AES, Haití, 1896, n. 94, fas. 15, f. 8v. 
que dispongo hacen suponer que no había temor de que la situación empeorase si España perdía la guerra. Como mucho podía esperarse una organización eclesiástica más libre y más eficaz, al estilo del pujante catolicismo norteamericano. De hecho, cuando se decide en Roma lanzar un concilio para toda Latinoamérica, el punto de referencia será el recientemente celebrado en Baltimo$\mathrm{re}^{49}$. Por una lado, la situación religiosa cubana no era especialmente buena: tras el esfuerzo renovador de Antonio María Claret, había vuelto a decaer especialmente el clero nativo. Por otra parte, la vieja identificación de principios del XIX entre Iglesia y España, volvía a estar presente tanto en el Caribe como en las Filipinas, con sus secuelas típicas: sectores de población independentistas se alejaban de la Iglesia y, al mismo tiempo, surgía un clero nacionalista enfrentado a la jerarquía.

En la práctica, entre una Iglesia controlada por el patronato - con presupuesto estatal- o una iglesia libre - -sin ninguna ayuda oficial-, lo segundo parecía más ventajoso. Así lo decía sin ambages el enviado pontificio en Santo Domingo cuando se esperaba que esta república decidiese unirse a Estados Unidos: mejor que vivir bajo la permanente opresión de un estado católico era la libertad de cultos bajo un gobierno protestante ${ }^{50}$.

De algún modo, ya antes de arriarse la bandera española, puede decirse que Roma había aceptado lo inevitable: en 1898, la S.C. de AA. EE. SS. recordaba que la carta apostólica Trans oceanum sobre los privilegios de América latina se debía aplicar en todas las Antillas y demás islas del mar Caribe ${ }^{5 l}$ sin excepción. El patronato legítimo había terminado en América.

\footnotetext{
49 Así se acuerda en la misma reunión de cardenales que aprueban la celebración de un concilio plenario para América Latina (cfr. AES, América, 1894, pos. 62, fas. 13, f. i)

so Sulle condizioni..., AES, AMERICA, 1894, Pos. 61, fas. 8, p. 601.

51 S.C. NN. EE. EE. declaratio authentica de vigore Litterarum Apostolicarum "Trans Oceanum» diei 18 Aprill 18697 in omnibus Antill et caeteri insuli maris Caraibici, 16 Augusti 1898, en Appendix ad schemna Decretorum pro Concilio Plenario Americae Latinae, Typis Vaticanis, [Roma] 1899, p. 543.

La América y la España Contemporánea Hispania Sacra $49(1997)$
} 